\title{
Differential gene transcription across the life cycle in Daphnia magna using a new all genome custom-made microarray
}

\author{
Bruno Campos ${ }^{1 *} \mathbb{D}$, Danielle Fletcher ${ }^{2}$, Benjamín Piña ${ }^{1}$, Romà Tauler $^{1}$ and Carlos Barata ${ }^{1}$
}

\begin{abstract}
Background: Unravelling the link between genes and environment across the life cycle is a challenging goal that requires model organisms with well-characterized life-cycles, ecological interactions in nature, tractability in the laboratory, and available genomic tools. Very few well-studied invertebrate model species meet these requirements, being the waterflea Daphnia magna one of them. Here we report a full genome transcription profiling of $D$. magna during its life-cycle. The study was performed using a new microarray platform designed from the complete set of gene models representing the whole transcribed genome of D. magna.

Results: Up to $93 \%$ of the existing 41,317 D. magna gene models showed differential transcription patterns across the developmental stages of D. magna, 59\% of which were functionally annotated. Embryos showed the highest number of unique transcribed genes, mainly related to DNA, RNA, and ribosome biogenesis, likely related to cellular proliferation and morphogenesis of the several body organs. Adult females showed an enrichment of transcripts for genes involved in reproductive processes. These female-specific transcripts were essentially absent in males, whose transcriptome was enriched in specific genes of male sexual differentiation genes, like doublesex.

Conclusion: Our results define major characteristics of transcriptional programs involved in the life-cycle, differentiate males and females, and show that large scale gene-transcription data collected in whole animals can be used to identify genes involved in specific biological and biochemical processes.
\end{abstract}

Keywords: Transcription, Microarray, Development, Daphnia, Ecotoxicogenomics, Moult, Functional annotation

\section{Background}

Unravelling the link between genes and environment across a life-cycle is a challenging goal. The full exploration of this link requires model organisms with wellcharacterized ecological interactions in nature, tractability in the laboratory and available genomic tools [1]. In Drosophila, the vast majority of genes are transcribed during the first embryonic stages due to the contribution of both maternally-inherited and zygote-produced mRNAs, while adult females and males display specific transcribed genes, consistent with the known transcriptional profiles of ovaries and testis [2,3]. Embryogenesis in the worm Caenorhabditis elegans elicits major transcriptional changes, particularly during the early and late

\footnotetext{
* Correspondence: brunocampus@gmail.com

${ }^{1}$ IDAEA-CSIC: Institute of Environmental Diagnosis and Water Research, CSIC, Barcelona, Spain

Full list of author information is available at the end of the article
}

stages, with a significant lower number of gene expression changes in mid-embryogenesis [4]. Males of $C$. elegans show a large number of highly expressed, malespecific genes, most of which being undetectable in any hermaphrodite stage [4]. Similar transcription gene patterns during embryogenesis and adult stages have been reported for many other species of sponges and insects $[5,6]$. In the above mentioned species, the observed high transcription of genes during embryogenesis are associated with morphogenesis, differentiation, and development, and larval or adult stages show different clusters of gene transcription often related with particular tissues and organs.

The waterflea Daphnia magna Strauss is a very useful species for both environmental and basic biology studies $[7,8]$. D. magna can be found in freshwater ecosystems all around the world, playing a relevant ecological role in the food web, both as a primary consumer and as a food 
source for predators, both vertebrates and invertebrates [9]. D. magna can be maintained in the lab as genetically uniform clonal lines through asexual parthenogenic reproduction, hereby reducing genetic variability and enabling the parallel analysis of functional and fitness changes in the same genotype in multiple environmental conditions [10]. D. magna and its close relative D. pulex are widely used as indicators of environmental quality [11], as models in evolutionary biology, and in the study of adaptive responses to environmental changes [12-16].

Daphnids genomes have recently received much attention from the scientific community, with the publication of two full genomes (D. pulex and D. magna) and two more species having their genomes partially sequenced $[1,17-20]$. The specific function of many genes, however, even in well studied organisms, is incomplete. It is not unusual to find a third of the genes in any genome to lack functional annotation [21, 22]. This lack of functional annotation is higher in newly sequenced organisms that often contain lineage-specific genes lacking homology with other assembled genomes [22, 23]. This is the case for D. magna and its close relative D. pulex, $[1,20,23,24]$. In D. pulex, one third of its genome comprises lineage-specific genes that lack orthologs in other eukaryote genomes and thus lack any functional annotation [20], and the situation is probably similar for the $D$. magna genome [17]. Transcriptomic studies in $D$. magna and related species have been up to now mostly conducted to evaluate the response of genes to environmental factors with few attempts to address transcriptomic changes across life-cycle stages [1, 25-34]. This means that little is known about the role of genes during its development, reproduction, and across sexes, which may compromise ecological and ecotoxicological interpretations.

D. magna has a well-known development and lifecycle stages, which combine parthenogenetic and sexual reproduction [35]. Parthenogenetic reproductive females allocate freshly formed eggs into the brood pouch every 3-4 days at $20{ }^{\circ} \mathrm{C}$, under optimal food conditions [10]. Freshly released eggs develop independently of the mother across 12 visually recognizable embryonic stages into free swimming juveniles [36] that are released by the mother just before it moults and allocates a new clutch of eggs into its brood pouch [10]. Juveniles, which are morphologically similar to adults, moult four or more times, depending on food conditions, before closing the circle by allocating the first clutch of eggs into their brood pouch [10]. In the ovary of a D. magna reproductive female co-exist clusters of pre and vitellogenic oocytes [35], the latter being provisioned with yolk during the intermoult interval to form the new clutch of eggs at the end of it, whereas the former will mature and became vitellogenic in the next reproductive cycle. Upon adverse conditions, D. magna females produce males whose haploid sperm can fecundate haploid oocytes to form an ephippia containing two sexually produced eggs, a process that can be triggered independently from environmental conditions by exposure to the crustacean juvenile hormone methyl farnesoate [35, 37]. Ephippia eggs can survive for decades in water bodies' sediments and develop into free-swimming female juveniles when conditions are favourable. Thus D. magna is also an excellent model to study large-scale gene transcription across development, reproduction and sexes to provide global relationships between transcription and life-cycle stages.

Novel developments of bioinformatic tools [38] and of DNA/RNA-seq technologies have allowed the publication of the Daphnia pulex full genome [20] and more recently of the full $D$. magna transcriptome [1]. Information reported by Orsini et al. [1] of approximately 42,000 gene validated models, including splicing forms, was used in this present study to design a new microarray, representing the full gene set of the D. magna transcriptome coupled with most up-to-date functional information. The new microarray platform was then used to study gene transcription patterns for the full transcriptome of $D$. magna across early and late embryonic stages, juveniles, reproductive females and males (Fig. 1).

\section{Results}

\section{Microarray performance}

The probe design was checked for specificity performing a complete probe match analysis against the $D$. magna original gene models. Using exact match criteria 3616 probes match to two or more transcripts. If allowing for 1-3 mismatches (5\% divergence) 5371 of the probes matched to two or more transcripts.

The microarray ability of representing real changes in transcription was checked performing $\mathrm{qPCR}$ on four relevant genes from three different pathways (Krebs cycle, tryptophan metabolism and ecdysteroid pathways). The results between the two technological platforms were highly correlated (Pearson correlation $>0.73, P<0$. $01, N=20$, Additional file 1: Figure S1).

\section{Differentially transcribed genes}

About 109,640 probes showed fluorescence values above the background. These probes belonged to 38,449 unique genes out of the 41,317 D. magna genes present in the microarray design (see Additional file 2 for further information regarding the non-expressed genes). Hierarchical clustering of fluorescence values for the 109,640 probes in all samples showed a good grouping of biological replicates (Fig. 2), a sign for good quality of the design. The analysis defined three main clusters: Cluster 1 composed by F2, F3 samples; Cluster 2 grouping E3, 


\section{a}

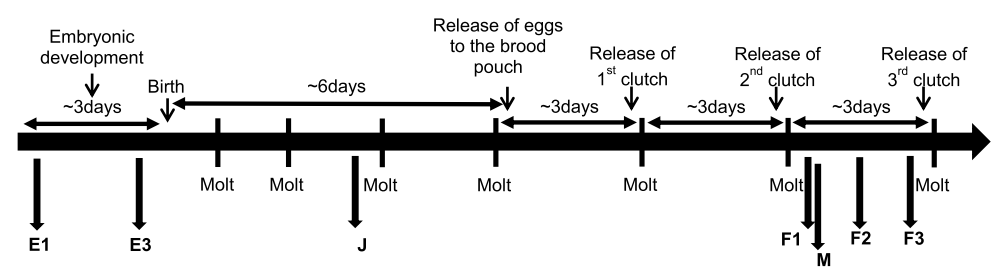

b
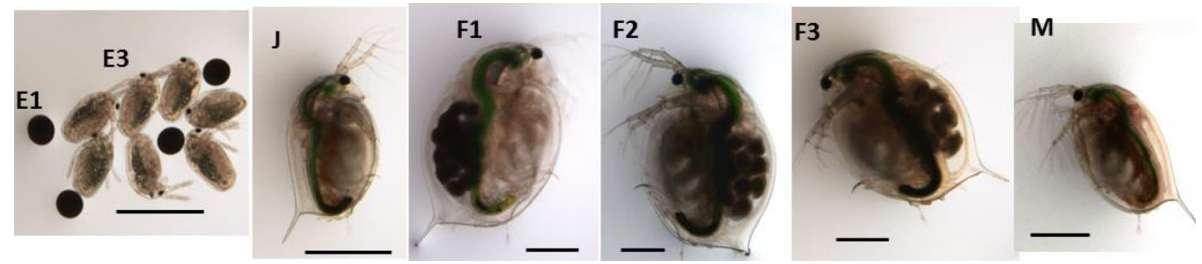

Fig. 1 Diagram representing the experimental design. a Seven life- stages were selected: embryos $<12 \mathrm{~h}$ after oviposition (Eggs 1, E1; corresponding to eggs of stage 1 following [1]), embryos within the last $12 \mathrm{~h}$ to be release as free swimming first instar juveniles (Eggs 3, E3; corresponding to embryos of stage 12 according to [1]); juvenile stage (J, animals of 4 days old), females F1, F2, F3 representing third brood females at the beginning, middle and end of their intermoult cycle, respectively. The final stage includes a reproductively active male (M) with 14 days. b images of the studied developmental stages, bars in each image are $1 \mathrm{~mm}$. Further details about the description of life-stages are in methods section

M, F 1 and J stages; and Cluster 3 including only E 1 samples.

The total number of differentially transcribed genes (DEG) can also be an important measure of how active the cells of an organism are during a particular life stage. The number of probes (DEP), and the unique genes these represent, differentially transcribed across lifestages was quite variable (Fig. 3 and Additional file 1: Tables S1 and S2). The highest number of DEP corresponded to the E1 stage (17881 DEP, representing 9663 unique genes), steadily decreasing to 10467 DEP (6013 Genes) in E3 and 4332 DEP (2893 Gene) in juvenile stages (Fig. 3). F1 females had the lowest number of DE compared to the all other life stages with 2100 DEP (1294 Genes), being that number increased to 3439 DEP (2292 genes) and 4141 (2900 genes) in F2 and F3, respectively. To allow a better comparison of transcriptomic changes across sexes all female stage $\mathrm{x}$ replicates were considered together, which totalled 14272 DEP (8026 genes). Furthermore, up to 6352 genes (11915 DEP) were differentially upregulated in both E1 and in F3 (E1F3, Fig. 3). Finally, males differentially expressed a total of 3980 DEP (2983 genes). In most life stages there were more up-regulated DEG than down regulated ones except for F1. Details of the expression levels of differentially transcribed probes and genes at the various studied life-stages are provided in Additional file 3.

The heat map of DEG included three clusters (Fig. 4a): the first one constituted by E1 samples, a second other including E3 and M samples, and a third cluster grouping the three female stages (J, F1, F2 and F3). Transcription patterns of up and down regulated DEGs in E1, E3, J, F1, F2, F3, F123 and M were stage-specific, whereas that of E1F3UP were up regulated in E1 and F3 (E1F3) and to a lesser extent in F2 and F1.

\section{Functional analysis}

A total of 25,019 (60\%) genes present in the microarray were functionally annotated to some level by using the three major databases (Drosophila, REFSEQ and Swissprot $\mathrm{KB}$ ), being 16,081 genes mapped to at least one GO Term and 7995 annotated to a KEGG-curated gene. Using a high stringency probability $(p<0.001)$, a total of 2905 distinct GO terms were enriched across the

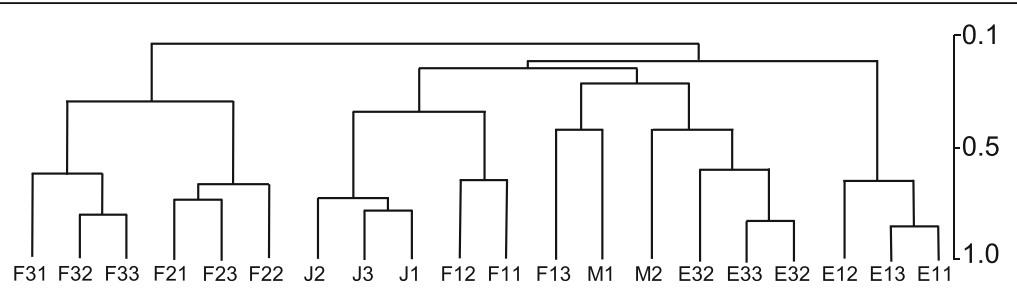

Fig. 2 Pearson hierarchical clustering of the studied samples. E1, E3, J, F1, F2, F3 and M refer, respectively, to eggs 1,3, juveniles, females 1,2,3 and males. Second numeral (i.e. E11, E12, E13) refer to replicate 1,2 and 3, respectively 


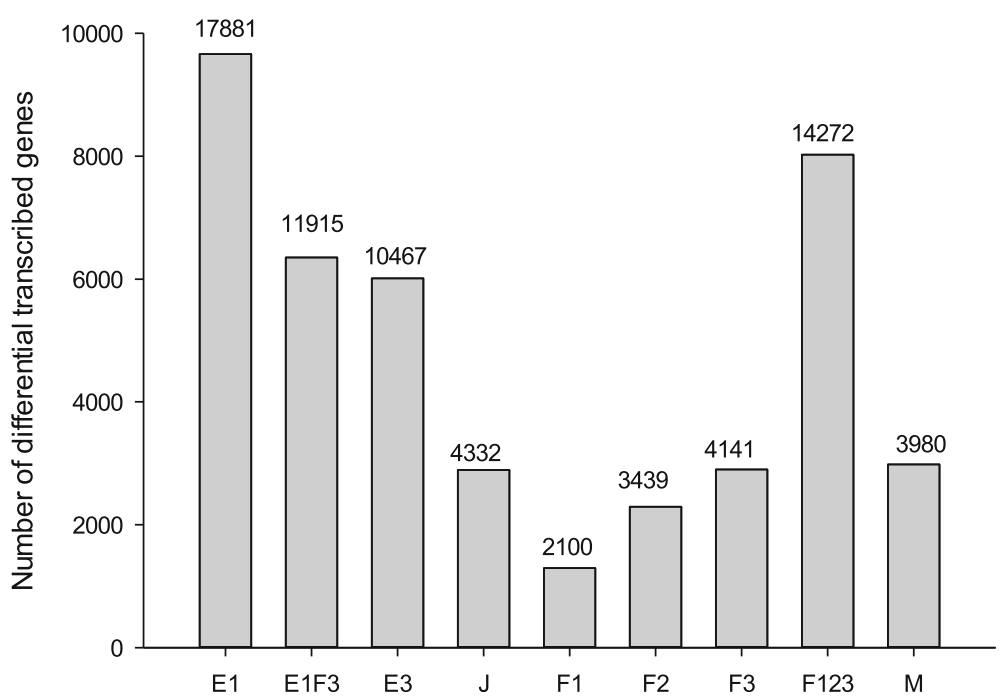

Fig. 3 Differentially transcribed genes across the studied D. magna life- stages. Numbers above each bar indicates number of probes. E1, E1F3, E3, F1, F2, F3 and F123 means respectively, eggs 1, eggs 1 \& females 3, eggs 3, females 1,2 and 3, the combined three female stages (F123). M stands for males
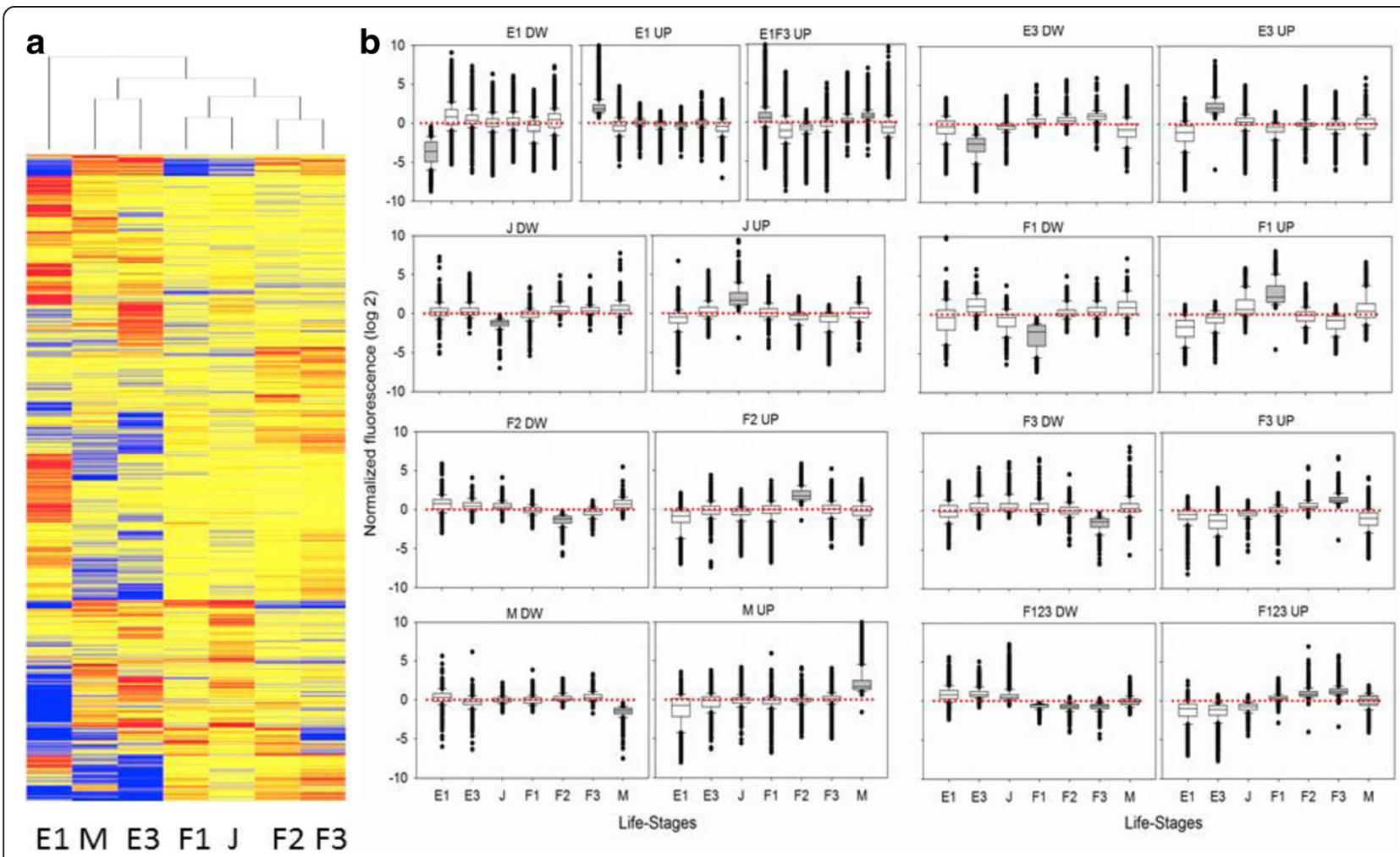

Fig. 4 Heat map of differentially transcribed genes clustered across the studied D. magna life- stages (a) and box-plot of transcription pattern of up and down regulated genes of each life-stage against the rest (b). In graph A red, blue and yellow colours indicated up, down and unchanged transcription levels. Grey boxes indicated the reference life-stage. For clarity analyses were conducted on averaged values of experimental replicates 
different life-cycle stages (Additional file 4), 364 of them (about 12\%) being common in at least two life-stages (Table 1). Selected GO terms and their coverage in each stage are shown in Table 2.

KEGG mapping of specific DEGs generally agreed with the identified GO terms, but they present a better overview on how the number of differentially expressed genes mapped to specific pathways along the development of the organism (Fig. 5 and Additional file 5).

\section{Discussion}

Most of the probes included in the microarray match a unique gene transcript with only about $3.2 \%$ of probes matching two or more gene transcripts. Furthermore correlation values of selected gene transcript levels between $\mathrm{qPCR}$ and microarray probes were high, even for low differentially transcribed genes, thus indicating a good quality of the probes, capable of reflecting even small changes in mRNA abundance.

More than $93 \%$ of the genes that are reported to be transcribed in D. magna genome [1] showed fluorescence values above background levels in at least one out of the seven studied life-cycle stages. Hierarchical clustering of samples and the number of differentially transcribed genes (Figs. 2 and 3) separated eggs from stage E1 that showed the greatest levels of differential transcribed genes $(34.5 \%$ of the 38,449 genes), reproductive females of stage F2 and F3 with up to $18.5 \%$ of the transcribed genes and the rest of life stages (E3, J, F1 and M) with the remaining 47\% of the gene transcripts. These three clusters had distinctive developmental/physiological characteristics. D. magna females transfer large amounts of resources including mRNA to their eggs to ensure their development and survival upon hatching [28, 39-42]. Therefore, E1 is likely to be enriched with genes associated to embryonic development and maternal transfer. Indeed up to 6352 genes were upregulated in E1 and in females F3 (E1F3 group in Fig. 3). This is in line with reported transcriptomic results in $D$.

Table 1 Number of common enriched Gene Ontology terms (GOs) across the studied life stages and in the cluster of genes upregulated in E1 and F3. Further information is in Additional file 4

\begin{tabular}{lllllllll}
\hline Life-stages & E1F3 & E3 & J & F1 & F2 & F3 & F123 & M \\
\hline E1 & 407 & 133 & 0 & 0 & 8 & 15 & 305 & 2 \\
E1F3 & & 121 & 2 & 4 & 5 & 33 & 75 & 1 \\
E3 & & & 25 & 18 & 16 & 24 & 190 & 2 \\
J & & & & 8 & 8 & 10 & 6 & 0 \\
F1 & & & & & 45 & 7 & 3 & 10 \\
F2 & & & & & & 10 & 30 & 1 \\
F3 & & & & & & 27 & 0 \\
F123 & & & & & & & & 0 \\
\hline
\end{tabular}

melanogaster, Anopheles and C. elegans, which found that the majority of genes were transcribed during early embryogenesis stages due to the contribution of both maternal and zygote ones [2-5]. The second cluster, grouping F2 and F3 females, can be considered representative of the most reproductive active stages, whereas life-stages included the third cluster (E3, J, F1 and M) are associated to high moulting activity and low-reproduction related processes $[43,44]$. The relative low levels of differentially transcribed genes in F1 females (4.6\% relative to the total), combined with an overrepresentation of down-regulated genes (see Additional file 1: Table S2) can be related to the fact that F1 organisms perform a reset of their metabolic and physiological processes at the beginning of the intermoult cycle $[43,44]$. Therefore, most of the specific differences showed in this stage could be related to de-activation of gene transcription.

Gene transcription across the studied life-stages (Fig. 4) also evidenced clear distinctive patterns across egg, juvenile and adult stages. Up regulated DEGs in reproductive females and males showed low transcription levels in the rest of life-stages whereas low transcribed ones were highly transcribed in the remaining stages. In the embryonic stage E3 and juveniles, genes having high or low levels of transcription changed little in the remaining stages. The early embryonic stage E1 showed two distinctive transcription patterns: a cluster of 9663 unique genes highly or poorly transcribed in that stage and a cluster of 6352 genes highly transcribed in that stage and in female stages F3 and F2. These results agree with those reported in Drosophila and C. elegans supporting the argument that many transcripts in E1 have a maternal origin $[2,3]$. The unique gene patterns identified in most life-stages and across sexes also support previous studies that associate these stages with specific subsets of genes being expressed in specific tissues and biological processes [2, 3].

\section{Gene function analysis}

E1 transcriptome included the highest number of significant GO terms (1380), mainly in categories related to division and proliferation, morphogenesis, homeostasis, and immune response (Table 2). Homeostasis is considered important to cells on high metabolic rates in which accumulation of some metabolites can become toxic. The enrichment in methylation-related transcripts may be linked to epigenetic processes, which are common during embryo development in Daphnia and other arthropods [2, 28, 45]. Interestingly the cluster of genes from E1 coming from a maternal origin (E1F3) were enriched with $829 \mathrm{GO}$ terms, $50 \%$ of them also present in E1 (Tables 1 and 2). Transcripts enriched in E3, with up to 1323 significant $\mathrm{GO}$ terms, also had important representation of GOs related with morphogenesis/organogenesis. They also include several GOs related to 
Table 2 Total and selected significant $(P<0.001)$ enriched Gene Ontology terms (GOs) of the differentially transcribed genes across the different studied life-cycle stages including genes of E1 from maternal origin (E1F3). N, \%Cov are number of probes and coverage. Further details are in Additional file 4. Stage abbreviations are explained in text

\begin{tabular}{|c|c|c|c|c|c|c|c|c|c|c|c|c|c|c|c|c|c|c|c|}
\hline \multirow{3}{*}{$\begin{array}{l}\text { Acession } \\
\text { Total } \\
\text { number }\end{array}$} & \multirow[t]{3}{*}{ GO Term } & \multirow{2}{*}{\multicolumn{2}{|c|}{$\frac{E 1}{1380}$}} & \multirow{2}{*}{\multicolumn{2}{|c|}{$\frac{\mathrm{E} 1 \mathrm{~F} 3}{829}$}} & & \multirow{2}{*}{\multicolumn{2}{|c|}{$\frac{J}{97}$}} & \multirow{2}{*}{\multicolumn{2}{|c|}{$\frac{\mathrm{F} 1}{145}$}} & \multirow{2}{*}{\multicolumn{2}{|c|}{$\frac{F 2}{146}$}} & \multirow{2}{*}{\multicolumn{2}{|c|}{$\frac{\mathrm{F} 3}{91}$}} & \multirow{2}{*}{\multicolumn{2}{|c|}{$\frac{F 123}{1004}$}} & \multirow{2}{*}{\multicolumn{2}{|c|}{$\frac{M}{27}$}} \\
\hline & & & & & & & & & & & & & & & & & & & \\
\hline & & $\mathrm{N}$ & $\begin{array}{l}\% \\
\mathrm{Cov}\end{array}$ & $\mathrm{N}$ & $\% \mathrm{Cov}$ & $\mathrm{N}$ & $\begin{array}{l}\% \\
\mathrm{Cov}\end{array}$ & $N$ & $\begin{array}{l}\% \\
\text { Cov }\end{array}$ & $\mathrm{N}$ & $\begin{array}{l}\% \\
\text { Cov }\end{array}$ & $\mathrm{N}$ & $\begin{array}{l}\% \\
\mathrm{Cov}\end{array}$ & $\mathrm{N}$ & $\begin{array}{l}\% \\
\text { Cov }\end{array}$ & $\mathrm{N}$ & $\begin{array}{l}\% \\
\mathrm{Cov}\end{array}$ & $\mathrm{N}$ & $\begin{array}{l}\% \\
\mathrm{Cov}\end{array}$ \\
\hline GO:0002176 & male germ cell proliferation & & & & & & & & & & & & & & & & & 9 & 0.5 \\
\hline GO:1901476 & $\begin{array}{l}\text { carbohydrate transporter } \\
\text { activity }\end{array}$ & & & & & & & & & & & & & 24 & 1.5 & & & 29 & 1.6 \\
\hline GO:0042302 & $\begin{array}{l}\text { structural constituent of } \\
\text { cuticle }\end{array}$ & & & & & 111 & 2.1 & & & 135 & 13.1 & 57 & 3.6 & 37 & 2.3 & & & 48 & 2.7 \\
\hline GO:0009838 & abscission & & & & & & & & & & & & & 10 & 0.6 & & & & \\
\hline GO:0097493 & $\begin{array}{l}\text { struct molec act conferring } \\
\text { elasticity }\end{array}$ & & & & & 83 & 1.6 & & & 97 & 9.4 & 51 & 3.3 & 30 & 1.9 & & & & \\
\hline GO:0032993 & protein-DNA complex & 218 & 2 & 93 & 1.6 & & & & & & & & & 39 & 2.5 & 107 & 1.7 & & \\
\hline GO:0042445 & hormone metabolic process & & & & & 223 & 4.2 & & & & & & & 81 & 5.1 & & & & \\
\hline GO:0048856 & $\begin{array}{l}\text { anatomical structure } \\
\text { development }\end{array}$ & 7415 & 68.7 & & & 3697 & 69.8 & & & & & & & 1128 & 71.5 & 4449 & 70.8 & & \\
\hline GO:0044851 & hair cycle phase & & & & & & & & & & & 14 & 0.9 & & & & & & \\
\hline GO:0048180 & activin complex & & & & & & & & & 5 & 0.5 & & & & & & & & \\
\hline GO:0022611 & dormancy process & & & & & & & & & 14 & 1.4 & & & & & & & & \\
\hline GO:0031395 & $\begin{array}{l}\text { bursicon neuropeptide } \\
\text { hormone complex }\end{array}$ & & & & & & & 11 & 0.6 & & & & & & & & & & \\
\hline GO:0072562 & blood microparticle & & & & & 55 & 1 & & & & & & & & & & & & \\
\hline GO:0042562 & hormone binding & & & & & 88 & 1.7 & & & & & & & & & & & & \\
\hline GO:0007626 & locomotory behavior & & & & & 337 & 6.4 & & & & & & & & & & & & \\
\hline GO:0004872 & receptor activity & & & & & 418 & 7.9 & & & & & & & & & & & & \\
\hline GO:0097458 & neuron part & & & & & 1135 & 21.4 & & & & & & & & & 1186 & 18.9 & & \\
\hline GO:0071944 & cell periphery & & & & & 2158 & 40.8 & & & & & & & & & 2529 & 40.3 & & \\
\hline GO:0042221 & response to chemical & & & & & 2366 & 44.7 & & & & & & & & & & & & \\
\hline GO:0009653 & $\begin{array}{l}\text { anatomical structure } \\
\text { morphogenesis }\end{array}$ & 4718 & 43.7 & 261.5 & 44.7 & 2370 & 44.8 & & & & & & & & & 2959 & 47.1 & & \\
\hline GO:0044767 & $\begin{array}{l}\text { single-organism } \\
\text { developmental process }\end{array}$ & 7414 & 68.7 & & & 3683 & 69.6 & & & & & & & & & 4523 & 72.1 & & \\
\hline GO:0002200 & $\begin{array}{l}\text { somatic diversification of } \\
\text { immune receptors }\end{array}$ & 70 & 0.6 & & & & & & & & & & & & & & & & \\
\hline GO:0002262 & myeloid cell homeostasis & 172 & 1.6 & & & & & & & & & & & & & & & & \\
\hline GO:0030496 & midbody & 217 & 2 & 154 & 2.6 & & & & & & & & & & & & & & \\
\hline GO:0002253 & $\begin{array}{l}\text { activation of immune } \\
\text { response }\end{array}$ & 370 & 3.4 & & & & & & & & & & & & & & & & \\
\hline GO:0032259 & methylation & 663 & 6.1 & 394 & 6.7 & & & & & & & & & & & & & & \\
\hline GO:0000989 & $\begin{array}{l}\text { transc fact act, transcription } \\
\text { factor binding }\end{array}$ & 704 & 6.5 & & & & & & & & & & & & & & & & \\
\hline GO:0000785 & chromatin & 783 & 7.3 & & & & & & & & & & & & & & & & \\
\hline GO:0002520 & $\begin{array}{l}\text { immune system } \\
\text { development }\end{array}$ & 914 & 8.5 & & & & & & & & & & & & & & & & \\
\hline GO:0008283 & cell proliferation & 1924 & 17.8 & & & & & & & & & & & & & 1174 & 18.7 & & \\
\hline GO:0016265 & death & 2139 & 19.8 & & & & & & & & & & & & & & & & \\
\hline
\end{tabular}


Table 2 Total and selected significant $(P<0.001)$ enriched Gene Ontology terms (GOs) of the differentially transcribed genes across the different studied life-cycle stages including genes of E1 from maternal origin (E1F3). N, \%Cov are number of probes and coverage. Further details are in Additional file 4. Stage abbreviations are explained in text (Continued)

\begin{tabular}{|c|c|c|c|c|c|c|c|c|c|c|c|c|c|c|c|c|c|c|c|}
\hline \multirow{3}{*}{$\begin{array}{l}\text { Acession } \\
\text { Total } \\
\text { number }\end{array}$} & \multirow[t]{3}{*}{ GO Term } & \multirow{2}{*}{\multicolumn{2}{|c|}{$\frac{\mathrm{E} 1}{1380}$}} & \multirow{2}{*}{\multicolumn{2}{|c|}{$\frac{E 1 F 3}{829}$}} & \multirow{2}{*}{\multicolumn{2}{|c|}{$\frac{E 3}{1323}$}} & \multirow{2}{*}{\multicolumn{2}{|c|}{$\frac{J}{97}$}} & \multirow{2}{*}{\multicolumn{2}{|c|}{$\frac{\mathrm{F} 1}{145}$}} & \multirow{2}{*}{\multicolumn{2}{|c|}{$\frac{F 2}{146}$}} & \multirow{2}{*}{\multicolumn{2}{|c|}{$\frac{\mathrm{F} 3}{91}$}} & \multirow{2}{*}{\multicolumn{2}{|c|}{$\frac{F 123}{1004}$}} & \multirow{2}{*}{\multicolumn{2}{|c|}{$\frac{M}{27}$}} \\
\hline & & & & & & & & & & & & & & & & & & & \\
\hline & & $\mathrm{N}$ & $\begin{array}{l}\% \\
\mathrm{Cov}\end{array}$ & $\mathrm{N}$ & $\% \operatorname{Cov}$ & $\mathrm{N}$ & $\begin{array}{l}\% \\
\mathrm{Cov}\end{array}$ & $\mathrm{N}$ & $\begin{array}{l}\% \\
\text { Cov }\end{array}$ & $\mathrm{N}$ & $\begin{array}{l}\% \\
\mathrm{Cov}\end{array}$ & $\mathrm{N}$ & $\begin{array}{l}\% \\
\mathrm{Cov}\end{array}$ & $\mathrm{N}$ & $\begin{array}{l}\% \\
\mathrm{Cov}\end{array}$ & $\mathrm{N}$ & $\begin{array}{l}\% \\
\mathrm{Cov}\end{array}$ & $\mathrm{N}$ & $\begin{array}{l}\% \\
\mathrm{Cov}\end{array}$ \\
\hline GO:0003006 & $\begin{array}{l}\text { developm proc. involved in } \\
\text { reproduction }\end{array}$ & 2267 & 21 & & & & & & & & & & & & & & & & \\
\hline GO:0048646 & $\begin{array}{l}\text { anatomical struct form } \\
\text { morphogenesis }\end{array}$ & 2681 & 24.9 & & & & & & & & & & & & & 1689 & 26.9 & & \\
\hline GO:0044085 & $\begin{array}{l}\text { cellular component } \\
\text { biogenesis }\end{array}$ & 4056 & 37.6 & & & & & & & & & & & & & & & & \\
\hline GO:0006950 & response to stress & 4684 & 43.4 & & & & & & & & & & & & & 2793 & 44.5 & & \\
\hline GO:0006807 & $\begin{array}{l}\text { nitrogen compound } \\
\text { metabolic process }\end{array}$ & 5825 & 54 & 3322 & 56.8 & & & & & & & & & & & & & & \\
\hline GO:0044422 & organelle part & 6354 & 58.9 & & & & & & & & & & & & & & & & \\
\hline GO:0016043 & $\begin{array}{l}\text { cellular component } \\
\text { organization }\end{array}$ & 6437 & 59.7 & & & & & & & & & & & & & & & & \\
\hline
\end{tabular}

response to chemicals (Table 2), perhaps preparing the organism to survive in the outside environment [46]. This stage also show an enrichment of GO terms related with sensorial and locomotion processes (neuronal activation and differentiation, hormonal metabolic processes and binding and locomotor behaviour), which would prepare the embryo for the free-swimming stage. The E3 transcriptome was also enriched in GOs related to cuticle constituents and elasticity, a functional category common to all the adult female stages. Transcriptome from the juvenile stage was annotated to 97 significantly enriched GO terms (Additional file 4), including the distinctive GO term "Bursicon neuropeptide hormone complex" (Table 2), which is related to the hardening of carapace [47]. This is in line with the fact that moulting and growth processes dominate in this stage over other biological functions such as reproduction [48]. Enriched GO terms from F1 transcriptome (145 GO terms in total) included two distinctive GO's: dormancy process and activin complex. The first GO term is possibly related to the re-setting of moulting and reproductive processes in which most bodily functions are "on hold" [49]. The activin complex GO term is directly related with the Follicle Stimulating Hormone (FSH) a key hormone to trigger the development of ovules [50]. This is a key process of extreme importance to the reproduction of these organisms showing that any impairment of these genes during this life stage period can be critical for the reproductive output. This is consistent with the fact that ovulation occurs precisely at the F1 stage [35]. In F2, specific transcripts were annotated to 146 significant GO terms, with one distinctive term, hair cycle phase, which can be linked in these organism to the formation of carapace and, possibly, also to hardening processes. Analysis of the F3 transcriptome identified 91 enriched GO terms, two of them with a high coverage (47\%, $71 \%$ coverage of the annotated probes DEG in this stage) and belonging to "Anatomical Structure Development or morphogenesis". These terms may be related to two processes: (1) the development of the ovary and formation and provisioning of eggs and (2) the maternal transfer of RNAs from the mother to the newly formed eggs to start development. Interestingly, a large fraction of probes annotated to Egg stages and of maternal origin (E1F3) also belong to this GO term. Another key term uniquely related to F3 was "Abcission", which in arthropods is involved in carapace shedding [51], a key event in the development of crustaceans that are only able to grow by periodically releasing the old carapace and the subsequent formation of a new one. This last GO term is likely related to the fact that females F3 are close to a moult event. Differentially transcribed genes of reproductive females (F123) belonged to 1004 GOs. Almost half (444) of those GO also existed in E1 and E3. Malespecific transcripts were annotated to 97 GO terms, including the unique category of "Male Germ Cell proliferation", which in turn includes the gene doublesex, linked in Daphnia to male sexual differentiation [52]. Males also present a high number of probes associated with carbohydrate transport activity, like F3, which can related to a high demand of energy for swimming in males [53] and to reproductive activities for females [48].

The metabolism-oriented KEGG pathway mapping (Fig. 5 and Additional file 5) shows a high number of DEG related to carbon, starch and sucrose, tryptophan and fatty acid metabolism in embryo (E1, E3 and 


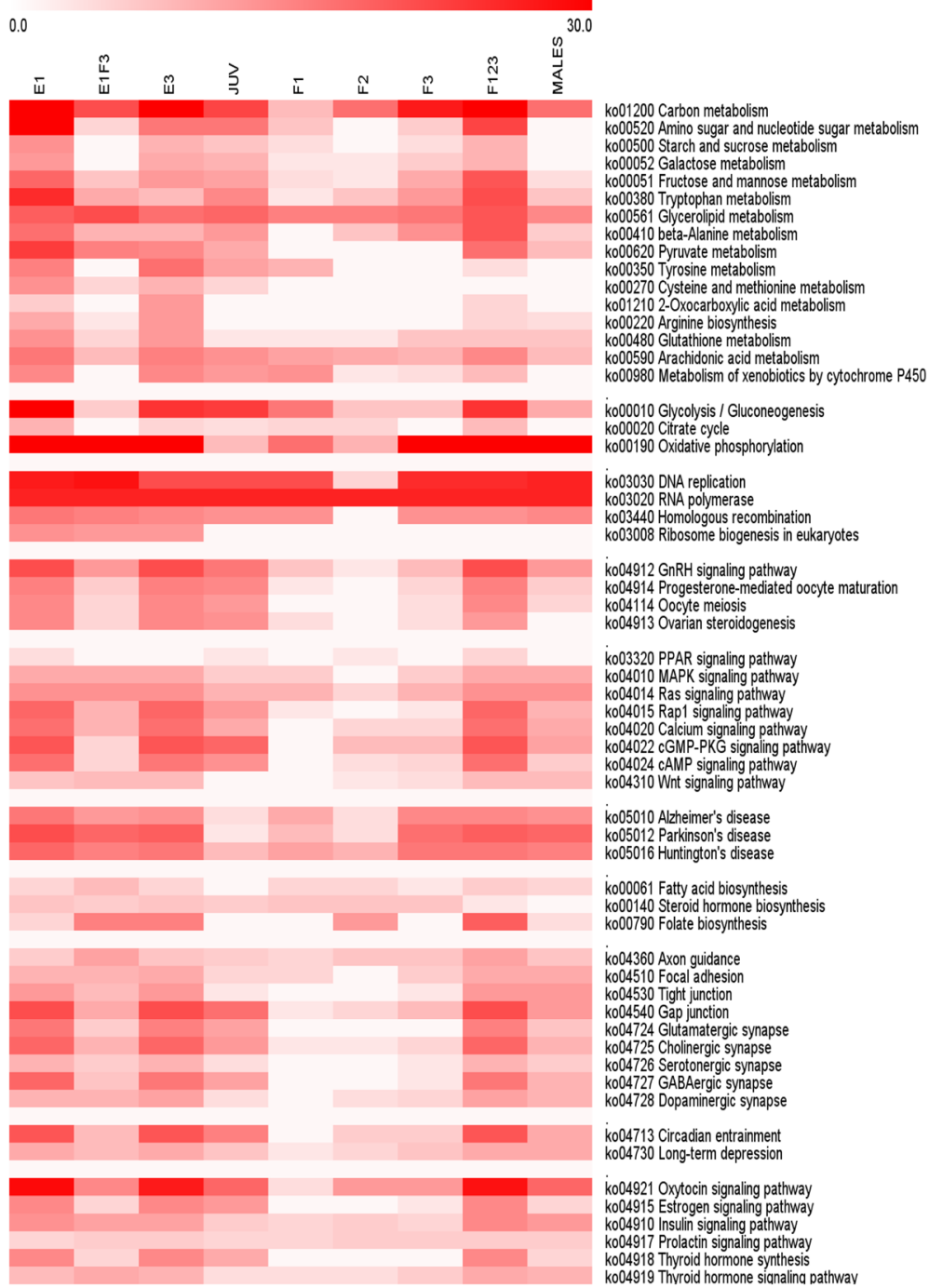

Fig. 5 Heat map of the enriched KEGG pathways among the differential transcribed genes in each life-stage and clusters. Scale refers to number of genes in each pathway. Further details can be found in Additional file 5

juvenile $(J)$ stages, while these numbers were reduced in adult males (M) and females (F1, F2, F3). Interestingly genes of E1 coming from a maternal origin were less enriched in the above mentioned metabolic pathway. Within the adult stages, F3 had the greatest number of DEGs belonging to KEGG metabolic related pathways, likely related to the animal needs to synthesize a new carapace and to finalize egg provisioning, both processes having a great demand of energy.

DEGs related to DNA replication were abundant in all life stages and in the cluster of E1 from maternal origin (E1F3) with except for F2. In the parthenogenicallyreproducing sister species Daphnia pulex, RNA and DNA concentrations were related to changes in metabolic activity associated with moulting cycle and ontogenetic development [54]. Ontogenic developmental processes are likely to dominate in embryo stages (E1, E3). Females F2 are just in the middle of the intermoult cycle, whereas the rest of free living stages (J, F1, F3) are likely to be just at the beginning or end of the moulting cycle.

An important point to consider when evaluating the quality of the data we are reporting of its functional analysis is the fact that males have no DEG mapped on females processes and hormones (Gonadotropin, progesterone, oocyte and ovarian steroidogenesis). All these processes were highly enriched in eggs, juveniles and F1,2,3.

Embryonic stages showed a high expression of genes annotated to many signalling pathways, like MAPK (response to stress), RAS (cellular signal transduction), RAP (vital for effective signal transduction), cAMP 
(second messenger important in several biological processes), and Wnt (signal transduction pathways made of proteins, extremely important for embryonic development). Genetic and molecular studies in Drosophila melanogaster over the last several years show that these signalling pathways are functionally conserved and that they participate in numerous processes during normal development [55-59].

Similarly, genes implicated in neuronal processes were highly expressed in egg and female stages. This is in line with the development of the neuronal system in metazoans along the embryonic stages [60]. Finally, hormonal processes related to Prolactin and insulin were evenly differentiated across life cycle stages, whereas genes belonging to thyroid hormone synthesis and oxytocin KEGG pathway, were differentially regulated in egg and female stages. Despite that genes and peptides of the above signalling pathways have been found in D. pulex and $D$. magna genome, little is known about their expression and function [61-63].

\section{Conclusions}

In this work we present a new microarray platform designed using the full set of gene models representing the complete genome of D. magna [1]. Up to $93 \%$ of the existing 41,317 D. magna gene models showed differential transcription patterns across the developmental stages of D. magna, from which more than $59 \%$ were functionally annotated. The transcriptome analysis show a large number of embryo-specific transcripts, likely related to the high metabolic rates needed for cellular multiplication and morphogenesis of several body organs, as inferred by the high number of DEG related to DNA, RNA and ribosome biogenesis. In adult females, most DEG were involved in reproductive processes and carapace shedding. Differentially transcribed genes in males were enriched in specific genes of male sexual differentiation genes, like doublesex [52]; consistently, they did not include hormonal female-related functional categories. These results are in line with those reported in Drosophila, showing that about $90 \%$ of transcription of embryo-specific transcripts occurs during the first hours of embryo development [2].

\section{Methods}

\section{Experimental animals and culture conditions}

All experiments were performed using a wellcharacterized single clone of D. magna (Clone F), maintained indefinitely as pure parthenogenetic cultures. Individual or bulk cultures of 10 animals/L were maintained in ASTM hard synthetic water [64] as described in [44]. Individual or bulk cultures were fed daily with Chorella vulgaris Beijerinck $\left(5 \times 10^{5}\right.$ cells $/ \mathrm{mL}$, respectively, corresponding to $1.8 \mu \mathrm{g} \mathrm{C} / \mathrm{mL}$; [10]). $C$. vulgaris was grown axenically in Jaworski/Euglena gracilis 1: 1 medium (CCAP, 1989). Algae were harvested in the exponential phase of growth, centrifuged and then re-suspended in ASTM hard water. The number of algal cells in freshly prepared medium was checked daily from absorbance measurements at $\lambda$ $=650 \mathrm{~nm}$ in a dual-beam spectrophotometer (Uvikon 941) using standard calibration curves based on at least 20 data points, with an $r^{2}>0.98$. The culture medium was changed every day, and neonates were removed within $24 \mathrm{~h}$. Photoperiod was set to $14 \mathrm{~h}$ light: $10 \mathrm{~h}$ dark cycle and temperature at $20 \pm 1{ }^{\circ} \mathrm{C}$.

For this study, females across six different developmental stages and one adult male stage were collected in triplicate. Embryonic samples were taken according to the embryonic development staging works by Mittmann et al. [36], while the free swimming stages were sampled following major physiological events. A graphic representation of these stages is depicted in Fig. 1. The first egg stage (E1) includes embryos $<6-8 \mathrm{~h}$ after ovideposition in stage 1 [36]. At Stage 1 the nucleus lies within non-transparent globular pale to greenish yolk granules and several larger oil drops. The egg is covered tightly by the chorion. The second embryonic stage selected (E3) corresponds roughly to stage 12 [36] and includes embryos within their last $12 \mathrm{~h}$ before the release from the mothers brood pouch. At this stage the embryonic development is mostly completed and is in the path of transformation to the first instar juvenile [36], being already able to swim. The choice of this stage was made to represent a neonate without the interference of feeding behaviour and or digestion processes. The third selected stage $(\mathrm{J})$ is a fourth instar juvenile or pre-adolescent stage. Animals of about 4 days old (with no ovary visible) [65], targeted to represent a full working organism but without the interference of reproductive processes.

Adult third clutch female stages (F1), (F2) and (F3) represent, respectively, reproductive females at the beginning $<12 \mathrm{~h}$ ), middle $(30 \mathrm{~h}<\mathrm{X}<40 \mathrm{~h})$ and end (> $66 \mathrm{~h}$ ) of their reproductive/intermoult cycle, which usually lasts 3 days at $20{ }^{\circ} \mathrm{C}$ with non-limiting food conditions as in the present study [44]. Females F1 were collected just after moult and release of the new clutch of newly formed eggs of stage 1 (i.e. E1 embryos) into their brood pouch $(<8 \mathrm{~h})$. Females F2 were sampled after approximately $36 \mathrm{~h}$ and F3 were collected within the last $24 \mathrm{~h}$ before moulting and releasing fully developed embryos. Females F3 thus hold embryos of stage 12 (our E3 embryos). Ovulation and egg provisioning occurs simultaneously during a single reproductive/intermoult cycle [35]. In females F1 pre-vitellogenic eggs pass to vitellogenic ones in the ovary and starts the egg provisioning, which is fully accomplished in F3. The development of embryos in the brood pouch also occurs simultaneously as ovulation and egg provisioning [35]. 
Females were de-brooded before being collected, by gently flushing water into the brood pouch. Removing the developing embryos from the brood pouch also removes their RNA, allowing for a much more robust profiling of the female adult stages [10]. The final samples include reproductively active males. These males were obtained exposing parthenogenic females to $0.5 \mu \mathrm{M}$ of methyl farnesoate [37]. After birth, the males were selected observing the size of the first antenna and let to grow until 14 days, representing a physiological status roughly coinciding with female stages.

\section{RNA extraction}

Total RNA was isolated from the samples using Trizol reagent (Invitrogen, USA) and following manufacturer protocols with slight modifications. After RNA isolation, DNAse treatment was performed according to manufacturer protocols, followed by a double phenol-chloroform and another chloroform extraction for further purification. RNA was precipitated using Sodium acetate and $100 \%$ ethanol, re-suspended in RNAse free water being quantity and quality checked using a NanoDrop D-1000 Spectrophotometer (NanoDrop Technologies, USA). Samples presenting a ratio 230/260-260/280 between 1 . 9-2.1 were selected. RNA integrity was checked using an Agilent 2100 Bioanalyzer (Agilent Technologies, USA). Only the samples showing invertebrate-adjusted RIN values above 9 were used for microarray analysis.

\section{Microarrays}

This new design was made using the gene models developed by Orsini et al. [1]. This gene set includes 41,317 gene models representing the full transcriptome of Daphnia magna. Four probes were designed for every gene, using the algorithms available in the e-array tool from Agilent (Palo Alto, USA). One of the probes was the best possible probe, while the other three were designed to represent a best geographical representation of the gene sequence, i. e., one probe representing the beginning of the sequence, another one representing the central part and the last the end part of the sequence. After probe design, redundancy was checked and in case of existence, redundant ones were removed. A set of 3500 random computer-generated probes were also added as further negative controls. Further e-array based quality controls were added, resulting in a microarray with 165,000 probes. This was then printed on a $4 \times$ 180,000 format (Agilent 66414 design; GPL22721). A total of three replicates per treatment were used. One $\mu \mathrm{g}$ of total RNA was used for all hybridizations. cDNA synthesis, cRNA labelling, amplification, and hybridizations were performed following the manufacturer's kits and protocols (Quick Amp labelling kit; Agilent, Palo Alto, CA). The Agilent one-color Microarray Based Gene Expression
Analysis v6.5 was used for microarray hybridizations according to the manufacturer's recommendations. Microarray images were generated by an Agilent high-resolution $\mathrm{C}$ microarray scanner. Data was resolved from microarray images using Agilent Feature Extraction software v10.7. Raw microarray data from this study have been deposited at the Gene Expression Omnibus Web site (www.ncbi.nlm. nih.gov/geo/) with accession number GSE90810.

\section{Gene expression analysis}

Microarray data were analysed using Gene Spring GX v13.0 software (Agilent, USA). Fluorescence data were normalized using quantile normalization and baseline transformation to the median of all samples.

The quantile 95 of the 3500 negative probes was calculated and this value was assumed as being the fluorescence background noise value of each sample. Only the probes having fluorescence values above background noise values $(109,640$ probes in total) were considered for further analyses. Sample Clustering of the total expressed genes across life-stages was analysed using the Multi-Experiment viewer MeV4 software [66] by hierarchical clustering using Pearson correlation algorithm.

Differentially transcribed probes (DEP) of D. magna individuals in a given life-stage were identified by pairwise comparison of the normalized replicated fluorescent levels of that stage against the other stages using Student $\mathrm{t}$ test $p<0.001)$ and a fluorescence change cut off of 1.5 -fold. The later term was calculated as the quotient between the power of two of the mean normalized fluorescence of both stages involved in the comparison. Only those probes whose normalized fluorescence changed significantly $\geq 1.5$ fold in all pairwise "stage" vs "all others" comparisons were considered. For a given stage probes having greater or lower normalized fluorescence values versus the rest of stages were considered up and down regulated. This approach was found to be more conservative than the combination of ANOVA approaches and the Benjamini-Hochberg false discovery rates correction. Finally, differentially transcribed genes (DEG) was defined as a non-redundant representation of the genes uniquely represented by at least one DEP. To determine genes present in E1 from maternal origin, differentially transcribes probes upregulated in both E1 and F3 were determined by comparing the normalized replicated fluorescent levels of both stages against the juvenile stage using Student $\mathrm{t}$ test $p<0.001$. Stages F3 and J were selected since F3 is the female stage where more resources from ovaries are allocated to eggs, whereas J can be considered an immature female stage [10].

\section{Validation of microarray results by qPCR}

Microarray results were validated with real-time quantitative polymerase chain reaction (qPCR). We selected 
four differentially expressed genes from different pathways/gene families which had already been successfully used in previous studies [46, 67]: Krebs cycle (isocytrate dehydrogenase, idh; ATP citrate lyase, ATPCL), tryptophan metabolism (dopamine decarboxylase, Ddc) and Ecdysteroid pathways (Ecdysone receptor, EcR b). The G3PDH gene (glyceraldehyde 3-phosphate dehydrogenase) was used as internal control (Housekeeping). Primers for each one of these genes were designed with Primer Express ${ }^{\circ}$ Software v3.0.1(Thermofisher, USA) and are provided elsewhere [46, 67]. qPCR was performed according to manufacturer's protocols.

\section{Gene model annotation}

For the optimal interpretation of transcriptional changes it is fundamental to have a functional annotation of all genes. To achieve this, all the 41,317 genes were searched for homology and functional annotation, including Gene Ontology (GO) and Kyoto Encyclopaedia of Genes and Genomes (KEGG). This was performed using Blast2Go Suit [26]. To maximize homology findings, this search was performed using BLASTX alignment algorithms (search protein databases against a translated nucleotide query). Search was performed using as target the three main databases of interest to our platform: Drosophila, RefSEQ and SwissprotKB. The three annotation sets were finally merged. The ultimate objective of re-annotation of the gene models was to improve as much as possible the functional annotation of these. This is the reason why we limited our search to the reference databases as these are the ones with most functional mapping. The full details of the annotation are available in GEO together with the microarray design (GPL22721).

\section{Additional files}

Additional file 1: Word file with the GPCR validation of the results in Figure $\mathrm{S} 1$ and the total number probes and genes of a given life-stage differential transcribed across the remaining ones and those up and down regulated in Tables S1 and S2 (DOCX $40 \mathrm{~kb}$ )

Additional file 2: Excel file with specific genes which were not transcribed (Fluorescence below background) throughout the development stages. (XLSX $89 \mathrm{~kb}$ )

Additional file 3: Excel file with specific probes and genes differentially transcribed across life-stages. (XLSX $26161 \mathrm{~kb}$ )

Additional file 4: Excel file with $\mathrm{GO}$ terms enriched across the different life-cycle stages (XLSX $411 \mathrm{~kb}$ )

Additional file 5: Excel file with KEGG terms across the different lifecycle stages (XLSX $5169 \mathrm{~kb}$ )

\section{Abbreviations}

DEG: Differentially expressed genes; DEP: Differentially expressed probes; E1: Egg in stage 1; E3: Egg in stage 3; F1, F2, F3: Reproductive females in stages 1, 2 and 3 respectively; F123: Combinations of females 1, 2, 3

\section{Acknowledgements}

We thank Prof. John Colbourne for the constructive discussions and kind review of this work and the Daphnia Genome Consortium for its support facilitating the access to $D$. magna gene models before freely available.

\section{Funding}

This study was supported by the Spanish MEC CTM2014-51985-R and the Advance grant of the European Research Council ERC-2012-AdG-320737. The funding bodies did not have a role in the design of the study, data collection, analysis, interpretation of data, writing the manuscript, nor the decision to publish.

\section{Availability of data and materials}

Microarray expression data has been deposited on NCBI Gene Expression Ominibus and are accessible through GEO accession number GSE90810.

\section{Authors' contributions}

$\mathrm{BC}$ collected and prepared the biological material; $\mathrm{BC}$, DF designed the microarray. $B C, C B, B P$ processed microarray and $q R T-P C R$ data. $B C, B P, R T, C B$ performed functional gene analyses. All authors contributed to the analysis of data and writing of the manuscript and approved the final manuscript.

\section{Ethics approval and consent to participate}

Not applicable.

\section{Competing interests}

The authors declare that they have no competing interests.

\section{Publisher's Note}

Springer Nature remains neutral with regard to jurisdictional claims in published maps and institutional affiliations.

\section{Author details}

${ }^{1}$ IDAEA-CSIC: Institute of Environmental Diagnosis and Water Research, CSIC, Barcelona, Spain. ${ }^{2}$ Agilent Technologies, Brighton, UK.

Received: 19 December 2017 Accepted: 25 April 2018

Published online: 18 May 2018

\section{References}

1. Orsini L, Gilbert D, Podicheti R, Jansen M, Brown JB, Solari OS, Spanier KI, Colbourne JK, Rush D, Decaestecker E. Daphnia magna transcriptome by RNA-Seq across 12 environmental stressors. Sci data. 2016;3:160030.

2. Arbeitman MN, Furlong EEM, Imam F, Johnson E, Null BH, Baker BS, Krasnow MA, Scott MP, Davis RW, White KP. Gene expression during the life cycle of Drosophila melanogaster. Science. 2002;297(5590):2270-5.

3. Graveley BR, Brooks AN, Carlson JW, Duff MO, Landolin JM, Yang L, Artieri CG, Van Baren MJ, Boley N, Booth BW, et al. The developmental transcriptome of Drosophila melanogaster. Nature. 2011;471(7339):473-9.

4. Boeck ME, Huynh C, Gevirtzman L, Thompson OA, Wang G, Kasper DM, Reinke $\mathrm{V}$, Hillier $\mathrm{LW}$, Waterston RH. The time-resolved transcriptome of $\mathrm{C}$. Elegans. Genome Res. 2016;26(10):1441-50.

5. Koutsos AC, Blass C, Meister S, Schmidt S, MacCallum RM, Soares MB, Collins $F H$, Benes V, Zdobnov E, Kafatos FC, et al. Life cycle transcriptome of the malaria mosquito Anopheles gambiae and comparison with the fruitfly Drosophila melanogaster. Proc Natl Acad Sci U S A. 2007;104(27):11304-9.

6. Qiu F, Ding S, Ou H, Wang D, Chen J, Miyamoto MM. Transcriptome changes during the life cycle of the red sponge, Mycale phyllophila (Porifera, Demospongiae, Poecilosclerida). Genes. 2015;6(4):1023-52.

7. Altshuler I, Demiri B, Xu S, Constantin A, Yan ND, Cristescu ME. An integrated multi-disciplinary approach for studying multiple stressors in freshwater ecosystems: Daphnia as a model organism. Integr Comp Biol. 2011; https://doi.org/10.1093/icb/icr103.

8. Miner BE, De Meester L, Pfrender ME, Lampert W, Hairston NG. Linking genes to communities and ecosystems: Daphnia as an ecogenomic model. Proc R Soc Lond B Biol Sci. 2012;279(1735):1873-82.

9. De Gelas K, De Meester L. Phylogeography of Daphnia magna in Europe. Mol Ecol. 2005;14(3):753-64.

10. Barata C, Baird DJ. Phenotypic plasticity and constancy of life - history traits in laboratory clones of Daphnia magna Straus: effects of neontal length. Funct Ecol. 1998;12:412-9. 
11. OECD. Guideline for testing of chemicals no 202. Daphnia. Acute immobilisation and reproduction test. Paris: Organization for Economic Cooperation and development; 2012.

12. Frisch D, Morton PK, Chowdhury PR, Culver BW, Colbourne JK, Weider LJ, Jeyasingh PD. A millennial-scale chronicle of evolutionary responses to cultural eutrophication in Daphnia. Ecol Lett. 2014;17(3):360-8.

13. Latta LC, Weider LJ, Colbourne JK, Pfrender ME. The evolution of salinity tolerance in Daphnia: a functional genomics approach. Ecol Lett. 2012;15(8):794-802.

14. Orsini L, Spanier Kl, De Meester L. Genomic signature of natural and anthropogenic stress in wild populations of the waterflea Daphnia magna: validation in space, time and experimental evolution. Mol Ecol. 2012;21(9):2160-75.

15. Scoville AG, Pfrender ME. Phenotypic plasticity facilitates recurrent rapid adaptation to introduced predators. Proc Natl Acad Sci. 2010;107(9):4260-3.

16. Stollewerk A. The water flea Daphnia-a'new'model system for ecology and evolution? J Biol. 2010;9(2):1

17. Colbourne JK, Singan VR, Gilbert DG. wFleaBase: the Daphnia genome database. BMC Bioinformatics. 2005;6:45.

18. Eads BD, Andrews J, Colbourne JK. Ecological genomics in Daphnia: stress responses and environmental sex determination. Heredity. 2008; 100(2):184-90.

19. Ebert D. A genome for the environment. Science. 2011;331(6017):539-40.

20. Colbourne JK, Pfrender ME, Gilbert D, Thomas WK, Tucker A, Oakley TH, Tokishita S, Aerts A, Arnold GJ, Basu MK. The ecoresponsive genome of Daphnia pulex. Science. 2011;331(6017):555-61.

21. Adams M. Open questions: genomics and how far we haven't come. BMC Biol. 2013;11:109.

22. Anton BP, Kasif S, Roberts RJ, Steffen M. Objective: biochemical function. Front Genet. 2014;5:210.

23. Ye Z, Xu S, Spitze K, Asselman J, Jiang X, Ackerman MS, Lopez J, Harker B, Raborn RT, Thomas WK, et al. A new reference genome assembly for the microcrustacean Daphnia pulex. G3. 2017;7(5):1405-16.

24. Routtu J, Hall MD, Albere B, Beisel C, Bergeron RD, Chaturvedi A, Choi JH, Colbourne J, Meester LD, Stephens MT, et al. An SNP-based secondgeneration genetic map of Daphnia magna and its application to QTL analysis of phenotypic traits. BMC Genomics. 2014;15(1):1033.

25. Piña B, Barata C. A genomic and ecotoxicological perspective of DNA array studies in aquatic environmental risk assessment. Aquat Toxicol. 2011;105(34 SUPPL):40-9.

26. Campos B, Garcia-Reyero N, Rivetti C, Escalon L, Habib T, Tauler R, Tsakovski S, Piña B, Barata C. Identification of metabolic pathways in daphnia magna explaining hormetic effects of selective serotonin reuptake inhibitors and 4nonylphenol using transcriptomic and phenotypic responses. Environ Sci Technol. 2013;47(16):9434-43.

27. Stanley JK, Perkins EJ, Habib T, Sims JG, Chappell P, Escalon BL, Wilbanks M, Garcia-Reyero N. The good, the bad, and the toxic: approaching hormesis in daphnia magna exposed to an energetic compound. Environ Sci Technol. 2013:47(16):9424-33

28. Lai KP, Li JW, Chan CYS, Chan TF, Yuen KWY, Chiu JMY. Transcriptomic alterations in Daphnia magna embryos from mothers exposed to hypoxia. Aquat Toxicol. 2016;177:454-63

29. Song Y, Rundberget JT, Evenseth LM, Xie L, Gomes T, Høgåsen T, Iguchi T, Tollefsen KE. Whole-organism transcriptomic analysis provides mechanistic insight into the acute toxicity of emamectin benzoate in Daphnia magna. Environ Sci Technol. 2016;50(21):11994-2003.

30. Giraudo M, Douville M, Cottin G, Houde M. Transcriptomic, cellular and life-history responses of Daphnia magna chronically exposed to benzotriazoles: endocrinedisrupting potential and molting effects. PLoS One. 2017;12(2):e0171763.

31. Kim BM, Ahn SH, Choi NR, Heo J, Kim H, Kwon KH, Lee YM, Rhee JS. Transcriptome profiles of Daphnia magna across to the different water chemistry of surface water of the Korean demilitarized zone. Toxicol Environ Heal Sci. 2017:9(3):188-98.

32. Toyota K, Williams TD, Sato T, Tatarazako N, Iguchi T. Comparative ovarian microarray analysis of juvenile hormone-responsive genes in water flea Daphnia magna: potential targets for toxicity. J Appl Toxicol. 2017;37(3):374-81.

33. Harney E, Plaistow SJ, Paterson S. Transcriptional changes during Daphnia pulex development indicate that the maturation decision resembles a rate more than a threshold. J Evol Biol. 2015;28(4):944-58.
34. Zhang YN, Zhu XY, Wang WP, Wang Y, Wang L, Xu XX, Zhang K, Deng DG. Reproductive switching analysis of Daphnia similoides between sexual female and parthenogenetic female by transcriptome comparison. Sci Rep. 2016;6:34241.

35. Zaffagnini F. Reproduction in Daphnia. Mem Ist Ital Idrobiol. 1987:45:245-84.

36. Mittmann B, Ungerer P, Klann M, Stollewerk A, Wolff C. Development and staging of the water flea Daphnia magna (Straus, 1820; Cladocera, Daphniidae) based on morphological landmarks. EvoDevo. 2014;5(1):1.

37. Olmstead AW, Leblanc GA. Juvenoid hormone methyl farnesoate is a sex determinant in the crustacean Daphnia magna. J Exp Zool. 2002; 293(7):736-9.

38. Gilbert DG. euGenes: a eukaryote genome information system. Nucleic Acids Res. 2002;30(1):145-8.

39. Little TJ, O'Connor B, Colegrave N, Watt K, Read AF. Maternal transfer of strain-specific immunity in an invertebrate. Curr Biol. 2003;13(6):489-92.

40. Wacker A, Martin-Creuzburg D. Allocation of essential lipids in Daphnia magna during exposure to poor food quality. Funct Ecol. 2007;21(4):738-47.

41. Schwarzenberger A, Von Elert E. What makes a man a man? Prenatal antennapedia expression is involved in the formation of the male phenotype in Daphnia. Dev Genes Evol. 2016;226(1):47-51.

42. Miyakawa $H$, Watanabe $M$, Araki M, Ogino $Y$, Miyagawa $S$, Iguchi T. Juvenile hormone-independent function of Krüppel homolog 1 in early development of water flea Daphnia pulex. Insect Biochem Mol Biol. 2018;93:12-8

43. Baird DJ, Barber I, Soares AMV, Calow P. An early life-stage test with Daphnia magna Straus: an alternative to the 21-day chronic test? Ecotoxicol Environ Saf. 1991;22:1-7.

44. Barata C, Baird DJ. Determining the ecotoxicological mode of action of toxicants from measurements on individuals: results from short duration chronic tests with Daphnia magna Straus. Aquat Toxicol. 2000;48:195-209.

45. Strepetkaitė D, Alzbutas G, Astromskas E, Lagunavičius A, Sabaliauskaitè R, Arbačiauskas K, Lazutka J. Analysis of DNA methylation and hydroxymethylation in the genome of crustacean Daphnia pulex. Genes. 2015;7(1):1-14.

46. Campos B, Altenburger R, Gómez C, Lacorte S, Pina B, Barata C, Luckenbach $T$. First evidence for toxic defense based on the multixenobiotic resistance (MXR) mechanism in Daphnia magna. Aquat Toxicol. 2014;148:139-51.

47. Kaltenhauser U, Kellermann J, Andersson K, Lottspeich F, Honegger HW. Purification and partial characterization of bursicon, a cuticle sclerotizing neuropeptide in insects, from Tenebrio molitor. Insect Biochem Mol Biol. 1995;25(4):525-33.

48. Glazier DS, Calow P. Energy allocation rules in Daphnia magna: clonal and age differences in the effects of food limitation. Oecologia. 1992; 90(4):540-9.

49. Baker DA, Russell S. Gene expression during Drosophila melanogaster egg development before and after reproductive diapause. BMC Genomics. 2009:10:242.

50. West BE, Parker GE, Savage JJ, Kiratipranon P, Toomey KS, Beach LR, Colvin SC, Sloop KW, Rhodes SJ. Regulation of the follicle-stimulating hormone $\beta$ gene by the LHX3 LIM-homeodomain transcription factor. Endocrinology. 2004;145(11):4866-79.

51. Gai M, Camera P, Dema A, Bianchi F, Berto G, Scarpa E, Germena G, Di Cunto F. Citron kinase controls abscission through RhoA and anillin. Mol Biol Cell. 2011;22(20):3768-78.

52. Kato $Y$, Kobayashi $K$, Watanabe $H$, Iguchi T. Environmental sex determination in the branchiopod crustacean Daphnia magna: deep conservation of a Doublesex gene in the sex-determining pathway. PLoS Genet. 2011;7(3):e1001345.

53. Brewer MC. Mating behaviours of Daphnia pulicaria, a cyclic parthenogen: comparisons with copepods. Philos Trans R Soc B. 1998;353(1369):805-15.

54. Gorokhova E, Kyle M. Analysis of nucleic acids in Daphnia: development of methods and ontogenetic variations in RNA-DNA content. J Plankton Res. 2002;24(5):511-22.

55. Halfar K, Rommel C, Stocker H, Hafen E. Ras controls growth, survival and differentiation in the Drosophila eye by different thresholds of MAP kinase activity. Development. 2001;128(9):1687-96.

56. Lane ME, Kalderon D. Genetic investigation of CAMP-dependent protein kinase function in Drosophila development. Genes Dev. 1993;7(7 A): 1229-43.

57. Stronach BE, Perrimon N. Stress signaling in Drosophila. Oncogene. 1999; 18(45):6172-82 
58. Wu CH, Nusse R. Ligand receptor interactions in the Wnt signaling pathway in Drosophila. J Biol Chem. 2002;277(44):41762-9.

59. Su YC, Treisman JE, Skolnik EY. The Drosophila Ste20-related kinase misshapen is required for embryonic dorsal closure and acts through a JNK MAPK module on an evolutionarily conserved signaling pathway. Genes Dev. 1998;12(15):2371-80.

60. Spitzer NC. Electrical activity in early neuronal development. Nature. 2006; 444.7120:707.

61. Dircksen H, Neupert S, Predel R, Verleyen P, Huybrechts J, Strauss J, Hauser F, Stafflinger E, Schneider M, Pauwels K, et al. Genomics, transcriptomics, and peptidomics of Daphnia pulex neuropeptides and protein hormones. J Proteome Res. 2011;10(10):4478-504.

62. Stafflinger E, Hansen KK, Hauser F, Schneider M, Cazzamali G, Williamson M, Grimmelikhuijzen CJP. Cloning and identification of an oxytocin/ vasopressin-like receptor and its ligand from insects. Proc Natl Acad Sci U S A. 2008;105(9):3262-7.

63. Wu W, Niles EG, LoVerde PT. Thyroid hormone receptor orthologues from invertebrate species with emphasis on Schistosoma mansoni. BMC Evol Biol. 2007;7:150.

64. ASTM. Standard methods for measuring the toxicity of sediment-associated contaminants with freshwater invertebrates. E 1706 -95b. In: Annual book of ASTM standards, vol. 11.05. Philadelphia: ASTM; 1999. p. 65-8.

65. Ebert D. A maturation size threshold and phenotypic plasticity of age and size at maturity in Daphnia magna. Oikos. 1994;69(2):309-17.

66. Howe E, Holton K, Nair S, Schlauch D, Sinha R, Quackenbush J. Mev: multiexperiment viewer. In: Biomedical informatics for cancer research. Boston: Springer; 2010. p. 267-77.

67. Campos B, Garcia-Reyero N, Rivetti C, Escalon L, Habib T, Tauler R, Tsakovski S, Piña B, Barata C. Identification of metabolic pathways in Daphnia magna explaining hormetic effects of selective serotonin reuptake inhibitors and 4nonylphenol using transcriptomic and phenotypic responses. Environ Sci Technol. 2013;47(16):9434-43.

Ready to submit your research? Choose BMC and benefit from:

- fast, convenient online submission

- thorough peer review by experienced researchers in your field

- rapid publication on acceptance

- support for research data, including large and complex data types

- gold Open Access which fosters wider collaboration and increased citations

- maximum visibility for your research: over $100 \mathrm{M}$ website views per year

At BMC, research is always in progress.

Learn more biomedcentral.com/submissions 